\title{
Opinion and Special Articles: Pain medicine
}

\section{A case for neurologists}

Kwo Wei David Ho, MD, PhD, and Roland Jones, MD

Neurology ${ }^{\circledR}$ 2018;91:483-486. doi:10.1212/WNL.0000000000006130

Correspondence

Dr. Ho

KwoWei.Ho@

neurology.ufl.edu
Chronic pain is one of most common chief complaints encountered by neurologists. In an American Academy of Neurology (AAN) survey of practicing US neurologists between 2000 and 2010 , about $50 \%$ of respondents manage headache, $20 \%$ manage chronic pain, and another $15 \%-20 \%$ manage spine-related conditions. ${ }^{1}$ As the secondary complaint, pain is also common in neurology practice, affecting $20 \%-40 \%$ of patients with primary neurologic diseases. ${ }^{2}$ In another survey, ${ }^{3} 91 \%$ of practicing neurologists expressed the need for more pain education and $89 \%$ agreed that more time should be given to residents' training in pain management. Despite the large percentage of the neurology patient population with chronic pain and the consensus on the need for more pain education among neurologists, the interest in pain management among neurology residents is stunningly low. According to a 2015 survey across neurology residents and fellows in the United States, only $1.2 \%$ out of all the residents intending to do fellowships are planning on pursuing pain medicine. ${ }^{4}$ This is concerning not only from the standpoint of neurology as a field, but more importantly from the perspective of patients with chronic pain, as they may be undertreated or ignored by neurologists. Indeed, in the position statement published by the AAN in 2001 (current as of $2013^{5}$ ), some neurologists avoid or undertreat patients with chronic pain, citing reasons varying from inadequate training or diagnostic capability to unfamiliarity with pain treatment methods and outcome measures. The statement advocated for enhanced pain education during residency and pain fellowship after residency. However, little has changed since the 2001 statement. The 2015 survey demonstrates the paucity of residents pursuing pain fellowships and a lack of role models during their residency. ${ }^{4}$ Many neurology residents graduate with little to no clinical exposure to pain management strategies outside of medication treatment.

In this article, we provide arguments for why neurologists should subspecialize in pain medicine and concrete solutions for possible ways to improve pain education during a neurology residency.

The wording "pain physician" used in this article refers to physicians whose primary practice involves treatment of pain conditions. They can come from a variety of training backgrounds, including, but not limited to, anesthesiology, physical medicine and rehabilitation, neurology, and psychiatry. These physicians typically receive training in pain fellowship, with skill sets ranging from medication management to nerve blocks and complex procedural training such as spinal cord stimulator trials and placement. For a neurologist with primary practice in pain medicine, the term "pain neurologist" is used.

\section{Why should neurologists become pain physicians?}

\section{Clinical experience with chronic pain}

Neurologists have tremendous clinical familiarity with pain and inherently make excellent pain physicians. Neurologists are trained in the neurologic pathways of pain, the pharmacology of numerous neuropathic pain medications, and neurologic dysfunction associated with the primary diagnosis. About half of neurologists routinely manage headache, 1 in 5 neurologists 
manage chronic pain, and another 1 in 5 manage spine related conditions with accompanying pain. ${ }^{1}$ This abundance of clinical experience is central to the role of a pain physician and indeed included in the curriculum of pain fellowships. If given the tools of an interdisciplinary pain physician, neurologists are well-positioned to excel among other disciplines involved in pain management.

\section{Good diagnostician}

Emphasis on diagnostic process is fundamental to neurologist training, perhaps more so than the other major disciplines entering pain medicine such as anesthesia and physical medicine and rehabilitation. This emphasis on diagnostic skills is essential to pain medicine with its multiple overlapping pain generators, and it may give neurologists an advantage in the field. Neurologists are inherently trained to pick up red flags on physical examination and separate those with primary painful process from those with possible underlying neurologic pathology. In a typical pain clinic, musculoskeletal pain makes up roughly $40 \%$ of patients' chief diagnosis, while neuropathic pain makes up another $30 \%{ }^{6}$ These neuropathic processes often carry considerable consequences if missed. For example, the physical examination is especially important with patients who have neck and back pain, as missed myelopathic processes can cause permanent neurologic damage if not intervened in a timely manner. In painful neuropathies, paraneoplastic or reversible nutritional processes can be missed and delay timely treatment. Neuromuscular conditions associated with myalgia and neuralgia can potentially lead to respiratory failure and death. These conditions underscore the importance of a full neurologic evaluation for any patient presenting with chronic pain.

\section{To both diagnose and treat}

Pain management is a field dominated by anesthesiologists. Anesthesiology residents rotate through acute pain and chronic pain services, both of which impart substantial exposure to interventional pain procedures. However, when it comes to neurologic diagnostic workup in the outpatient setting, there is comparatively little training for non-neurologists in the pain fellowship curriculum. On the other hand, neurology residents are conventionally trained in examination and diagnosis but receive relatively little procedural training central to interventional pain management. Traditionally, anesthesiologists depend on neurologists for diagnostic workup if they detect certain red flags on physical examination, while neurologists depend on anesthesiologists for performing pain procedures. This model works when anesthesiologists can pick up red flags on physical examination, and when neurologists know the indications for procedures. The model breaks down when either of these assumptions fails. When red flags are not noticed, permanent neurologic damage can take place. When a neurologist is not familiar with indications of interventional pain treatment, such as cervical medial branch block for cervicogenic headache, a patient's pain may go undertreated indefinitely. This outdated model is doing a significant disservice to our patients, as it may prolong the suffering and the overall financial burden of patients with chronic pain.
As pain fellowships become increasingly available to neurologists, the overall clinical field of neurology will become better equipped to address these issues. Pain articles will make their way to neurology journals with increasing frequency and pain management courses could become commonplace at our annual meetings. Diagnostic interventional pain procedures such as selective nerve blocks could be merged into the armamentarium of clinical neurologic decision-making algorithms. Future pain research, under the culture of neurology, could enhance the style and body of aggregate pain-related data. With procedural training, a neurologist will be able to master the triad of clinical examination and diagnosis, pharmacologic management of chronic pain, and interventional management. From the standpoint of a referring doctor, a pain-trained neurologist would be the single best one-doctor solution for referring a patient for pain management regardless of the etiology. The referring physician would be assured that his or her patients are fully evaluated neurologically and then treated with all possible modalities. Expensive testing and pain medications could be centralized without duplication by various providers such as intervention-only pain physicians, consulting neurologists, primary care physicians, and rheumatologists.

\section{How to improve pain education during residency}

In this section, we provide concrete solutions for improving pain education during a typical neurology residency (figure).

\section{Make pain medicine a required clinical rotation}

In a typical neurology residency, little time is dedicated to pain management training. ${ }^{3}$ Only $5 \%$ of the surveyed programs required a pain clinic rotation, while $62 \%$ of residents received no training in a pain clinic. This contrasts with a large majority (89\%) of practicing neurologists stating the need for more pain-related training during residency.

Because of the scarcity of pain neurologists, most neurology programs do not have pain-trained neurologists. Unlike other subspecialties in neurology, such as headache or neuroimmunology, lack of a pain neurologist in the department means no exposure to interventional pain treatment for residents. Although most pain medicine programs are under the department of anesthesiology, neurology residency programs could establish clinical rotations for their residents in those local pain clinics. If a local pain clinic is not available, residencies could establish away rotations for their residents at the nearby pain clinics, perhaps offering adjunct professorships to collaborating instructors and employing the use of temporary lodging in extended stay facilities. This model is often utilized by other disciplines seeking to train their residents and fellows in essential but locally unavailable skill sets. These methods all buttress the goal of exposing neurology residents to a multidisciplinary pain treatment model so that they may become 


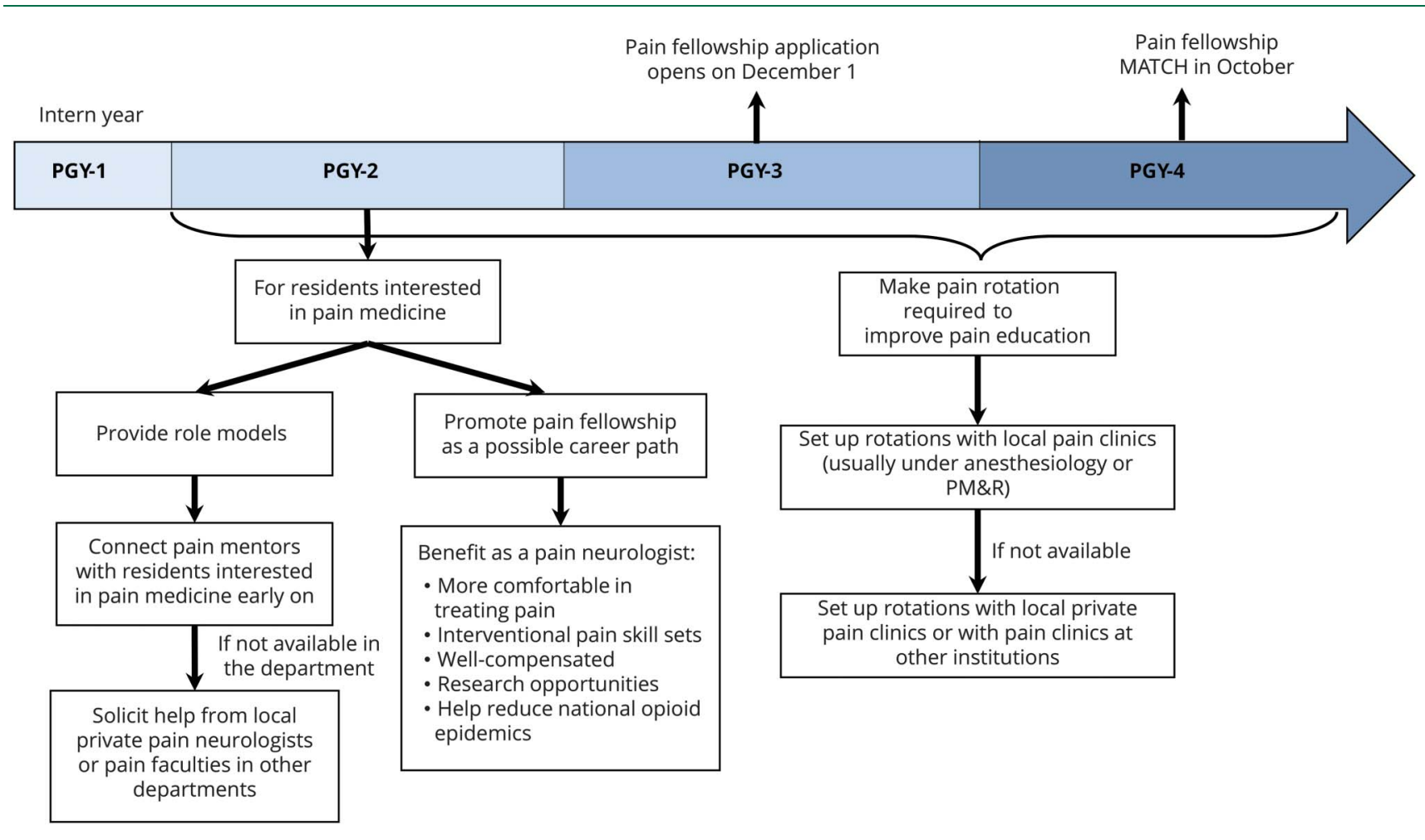

acquainted with the examination, potential diagnoses and treatment, and indications for referral. These include exposures to interventional pain procedures, physical therapy, pain psychology, and weight management.

\section{Providing role models}

According to a 2015 AAN survey, ${ }^{4}$ only $0.5 \%$ of residents have role models working in pain medicine. This figure may be secondary to a substantial lack of neurology faculty able to teach pain medicine. One study reported that only $29 \%$ of programs have a pain neurologist on faculty. ${ }^{3}$ Given that pain neurologists are not widely available, programs should help residents seek out role models early on, even if that means soliciting assistance from pain neurologists in the community.

\section{Promoting pain fellowship as a possible career path}

Pain fellowships offer a variety of benefits to a neurologist. Pain fellowship training offers interventional skill sets that typical neurology residencies do not supply, making one comfortable in treating patients with a variety of painful conditions. Pain specialists are typically well-compensated, which provides more time for research and job satisfaction. From the national level, pain neurologists can play a role in reducing the current opioid epidemic by providing interventional and appropriate multidisciplinary treatment while reducing opioid usage.

There are approximately 100 pain fellowship programs taking new fellows at the time of this writing. In an article on pain medicine fellowships for neurologists, ${ }^{7}$ few non-neurology- based pain fellowships accepted neurology applicants in 2006. This is not the case anymore. Although about $90 \%$ of pain fellowships are based under the departments of anesthesiology, most programs accept a wide range of backgrounds, including anesthesiology, physical medicine and rehabilitation, neurology, and psychiatry.

\section{Discussion}

Neurologists are excellent diagnosticians and have abundant experience with medication management for chronic conditions. With training in interdisciplinary pain medicine, they would perhaps be the most well-rounded pain management physicians. However, there seems to be a lack of interest among residents despite calls for better education. We provide practical advice to residency programs in hopes of generating pain management interest in their residents and incorporating more exposure to pain education during neurology residency. With this increased exposure and educational integration, we could see an increasing proportion of neurology residents entering this exciting field.

\section{Author contributions}

Kwo Wei David Ho conceptualized and drafted the manuscript. Roland Jones critically reviewed the article and provided revisions for intellectual content.

\section{Study funding}

No targeted funding reported. 


\section{Disclosure}

K. Ho serves on the editorial team of the Neurology ${ }^{\circledR}$ Resident \& Fellow section. R. Jones reports no disclosures relevant to the manuscript. Go to Neurology.org/ $\mathrm{N}$ for full disclosures.

\section{References}

1. Adornato BT, Drogan O, Thoresen P, et al. The practice of neurology, 2000-2010: report of the AAN Member Research Subcommittee. Neurology 2011;77:1921-1928.

2. Borsook D. Neurological diseases and pain. Brain 2012;135:320-344.
3. Galer BS, Keran C, Frisinger M. Pain medicine education among American neurologists: a need for improvement. Neurology 1999;52:1710-1712.

4. American Academy of Neurology. 2015 Fellowship Survey Report. Minneapolis: American Academy of Neurology; 2015.

5. American Academy of Neurology Ethics, Law, and Humanities Committee. Ethical considerations for neurologists in the management of chronic pain. Neurology 2001; 57:2166-2167.

6. Mailis-Gagnon A, Yegneswaran B, Lakha SF, et al. Pain characteristics and demographics of patients attending a university-affiliated pain clinic in Toronto, Ontario. Pain Res Manag 2007;12:93-99.

7. Lalani I. Emerging subspecialties in neurology: pain medicine. Neurology 2006;67: $1522-1523$.

\section{Disputes \& Debates: Rapid online correspondence}

The editors encourage comments on recent articles through Disputes \& Debates:

Access an article at Neurology.org/ $N$ and click on "COMMENT" beneath the article header. Responses will be posted within 3 business days.

Before submitting a comment to Disputes \& Debates, remember the following:

- Disputes \& Debates is restricted to comments about studies published in Neurology within the last eight weeks

- Read previously posted comments; redundant comments will not be posted

- Your submission must be 200 words or less and have a maximum of five references; reference one must be the article on which you are commenting

- You can include a maximum of five authors (including yourself)

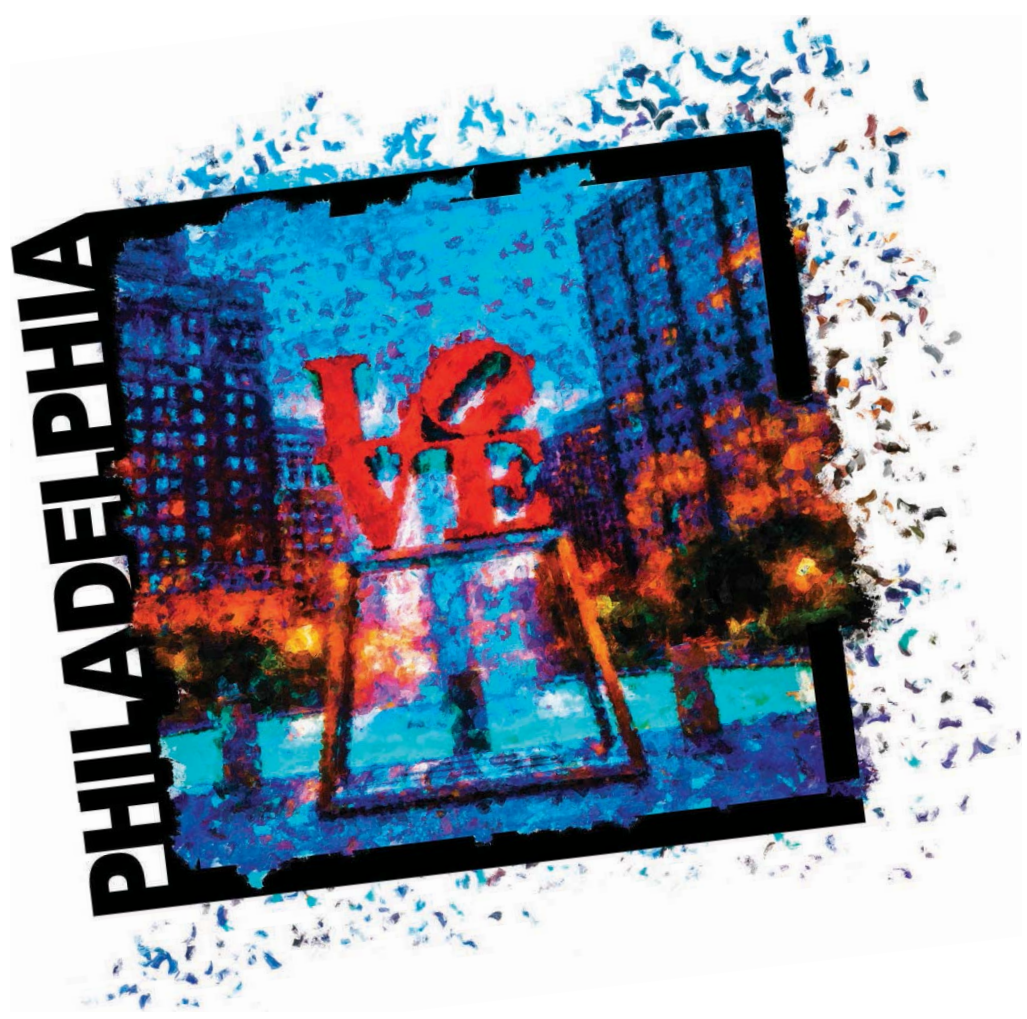

ADVANCING NEUROLOGY. ADVANCING YOU.

\section{IMPORTANT DATES AND DEADLINES}

Don't miss these important dates for the 2019 AAN Annual Meeting, set for May 4-10, 2019, in Philadelphia.

Learn more at AAN.com/view/AM19

- Abstract Submission Deadline:

October 22, 2018

- Awards Application Deadline:

October 24, 2018 


\section{Neurology}

\section{Opinion and Special Articles: Pain medicine: A case for neurologists \\ Kwo Wei David Ho and Roland Jones \\ Neurology 2018;91;483-486 \\ DOI 10.1212/WNL.0000000000006130}

This information is current as of September 3, 2018

\section{Updated Information \& Services}

\section{References}

Subspecialty Collections

Permissions \& Licensing

Reprints including high resolution figures, can be found at: http://n.neurology.org/content/91/10/483.full

This article cites 6 articles, 4 of which you can access for free at: http://n.neurology.org/content/91/10/483.full\#ref-list-1

This article, along with others on similar topics, appears in the following collection(s):

\section{All Pain}

http://n.neurology.org/cgi/collection/all_pain

Information about reproducing this article in parts (figures,tables) or in its entirety can be found online at:

http://www.neurology.org/about/about_the_journal\#permissions

Information about ordering reprints can be found online:

http://n.neurology.org/subscribers/advertise

Neurology ${ }^{\circledR}$ is the official journal of the American Academy of Neurology. Published continuously since 1951 , it is now a weekly with 48 issues per year. Copyright @ 2018 American Academy of Neurology. All rights reserved. Print ISSN: 0028-3878. Online ISSN: 1526-632X.

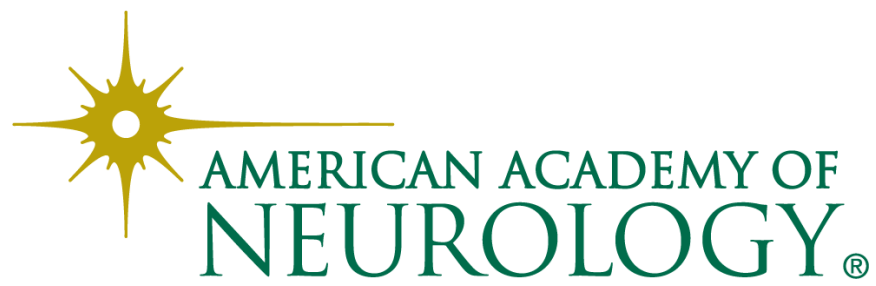

